\title{
Comparison of push-in and push-out tests for measuring interfacial shear strength in nano-reinforced composite materials
}

\author{
Carlos Medina M, Jon M Molina-Aldareguía, \\ Carlos González, Manuel F Melendrez, Paulo Flores and \\ Javier LLorca
}

\begin{abstract}
The influence of the carbon nanotubes (CNTs) content on the fiber/matrix interfacial shear strength (IFSS) in glass/fiber epoxy composites was measured by means of push-in and push-out tests. Both experimental methodologies provided equivalent values of the IFSS for each material. It was found that the dispersion of CNTs increased in IFSS by $19 \%$ in average with respect to the composite without CNTs. This improvement was reached with 0.3 wt.\% of CNTs and increasing the CNT content up to $0.8 \mathrm{wt}$.\% did not improve the interface strength.
\end{abstract}

\section{Keywords}

Interfacial shear strength, push-in test, push-out test, carbon nanotubes, nanocomposites

\section{Introduction}

Fiber-reinforced polymers contain a large volume fraction of small diameter fibers, leading to a very large interface area per unit volume. As a result, the composite mechanical performance depends not only on the matrix and fiber mechanical properties and spatial distribution but also on the interface strength. A good interfacial bonding ensures an efficient load transfer from the matrix to the fiber and the mechanical properties in direction perpendicular to the fibers as well as the shear strength and the impact and the fatigue resistance are particularly sensitive to the interface strength. ${ }^{1-6}$

Fiber/matrix interface bonding takes place by different mechanical (interlocking), physical, and chemical mechanisms and is also influenced by the thermal residual stresses and the design of stronger interfaces is a very active research area. ${ }^{7}$ The fiber/matrix interaction at the interface occurs at submicron level, and carbon nanotubes (CNTs) have been used as additives to improve fiber/matrix adhesion. One approach has covered the fiber surface with CNTs to improve adhe$\operatorname{sion}^{2,4,5,8-10}$ while other strategies use CNTs as modifiers of the polymeric matrix, ${ }^{6,11-13}$ moreover in Godara et al. ${ }^{2}$ both techniques are mixed. In all cases, it has been shown that the addition of CNTs can increase resin tenacity and improve interface properties because CNTs improve the adhesion of the resin to the fiber in the interfacial region. In addition, Yang et al. ${ }^{14}$ demonstrate numerically the positive effect of the amount of CNTs on the interfacial shear strength (IFSS).

The standard figure of merit to characterize the mechanical properties of the fiber/matrix interface is the IFSS. Despite the importance of this parameter, there is no consensus on the best technique to measure the IFSS, nor there is a standard procedure. Interfacial properties can be evaluated by micromechanical techniques as well as by macromechanical tests. 
Macromechanical tests, such as the interlaminar shear strength test according to ASTM D2344 standard, have been used to assess the interface properties but can only provide an indirect, qualitative estimation due to the complex and multiscale interactions involved in the failure mechanism. ${ }^{5}$ On the contrary, micromechanical tests measure directly the IFSS by debonding a single fiber from the matrix. These single fiber tests are better placed to understand the mechanical interaction of fiber/matrix/interface and for comparison with numerical approaches. The single fiber test can be divided into two groups, depending on whether the test is carried out in single fiber composites prepared for this purpose or in actual composite samples. The fragmentation test, ${ }^{8,15}$ the pull-out test ${ }^{16,17}$ and the microdroplet test ${ }^{13,18-20}$ belong to the first category, while the pushout test ${ }^{2,21-23}$ and the push-in test ${ }^{24-28}$ stand in the second one. It is nowadays accepted that the values of the IFSS obtained with these tests are good indicators of the interface strength from a comparative viewpoint but it is also recognized that the local environment in the single fiber composites is very different from the actual environment within the composite. ${ }^{8,13,29-31}$ Moreover, it has been shown that the local fiber volume fraction, the thermal residual stresses, and the polymer crosslink density (which are different in single fiber composites) can lead to significant changes in the properties of the interface. ${ }^{27,28}$ Therefore, the push-in and push-out tests, which are performed directly on composite samples, stand as the best options to obtain quantitative values of the IFSS but it is necessary to ensure that the IFSS values obtained from both tests are equivalent.

In this investigation, the influence of CNT dispersion on the fiber/matrix IFSS in a glass-fiber polymer-matrix composite was measured by means of the push-in and push-out tests. It was found that both testing techniques provided equivalent values of the IFSS for different volume fractions of CNTs dispersed in the matrix (from 0 to $0.8 \mathrm{wt} . \%$ ). It was also found that the presence of CNT improved the interface properties by $19 \%$ in average for $0.3 \mathrm{wt} . \%$. Further addition of CNTs did not enhance the interface properties.

\section{Materials and experimental techniques}

\section{Materials}

The composite material was fabricated with an L20 epoxy resin with EPH 161 hardener (Momentive, USA) distributed by R\&G composites (Germany). The reinforcement was an ECG $755 / 0$ glass fiber plain weave unidirectional in warp direction with an areal weight of $220 \mathrm{~g} / \mathrm{m}^{2}$. The average glass fiber diameter was $9 \mu \mathrm{m}$ and the elastic modulus $75 \mathrm{GPa}$.
Table I. Codes of fabricated materials.

\begin{tabular}{ll}
\hline Code & Material \\
\hline EGI & Epoxy + fiberglass \\
EG2 & Epoxy + MB CNT $0.3 w t . \%+$ fiberglass \\
EG3 & Epoxy + MB CNT $0.5 w t . \%+$ fiberglass \\
EG4 & Epoxy + MB CNT $0.8 w t . \%+$ fiberglass \\
\hline
\end{tabular}

The multiwall CNTs (not functionalized) were introduced in the composite using the Epocyl XC 128-06 CNT masterbatch (Nanocyl, Belgium). ${ }^{32,33}$ The masterbatch was diluted by factors of 17, 10, and 6 to obtain concentrations of CNTs in the composite of $0.3,0.5$, and $0.8 \mathrm{wt} . \%$, respectively.

Composite plates comprising 25 plies of $100 \times 100$ $\mathrm{mm}^{2}$ were manufactured by resin transfer molding (RTM) using a spacer of $4.3 \mathrm{~mm}$ thickness. The fiber volume fraction was $50 \%$ computed according to the ASTM D3171 standard. During the fabrication, prior to resin injection, the nanotube masterbatch was diluted in L20 resin. The mixture was homogenized by mechanical stirring for $10 \mathrm{~min}$ at a speed of $1000 \mathrm{r} /$ min. Subsequently, the resin was mixed with a hardener in a $4: 1$ ratio and the mixture was degassed by ultrasounds for $15 \mathrm{~min}$ and then injected into the mold. Different proportions of nanotube masterbatch and L20 resin were used to reach $0.3,0.5$, and 0.8 wt. $\%$ of CNTs dispersed in the matrix. Curing and post-curing took place at room temperature for $24 \mathrm{~h}$ and at $100^{\circ} \mathrm{C}$ for $15 \mathrm{~h}$ in an oven, respectively. These materials are summarized in Table 1, together with the corresponding codes used in the study.

\section{Experimental techniques}

A Hysitron TI 950 triboindenter instrument with a diamond flat conical tip of $5 \mu \mathrm{m}$ in diameter was used for the micromechanical tests. Push-in and push-out tests were performed under displacement control at $50 \mathrm{~nm} / \mathrm{s}$. For the push-in test, samples were cut from the composite plate and embedded in epoxy resin to facilitate handling during polishing. Surfaces perpendicular to the fibers were polished with a sequence of silicon carbide papers of 1000, 2000, and 4000, and finished with polishing pastes of 0.3 and $0.1 \mu \mathrm{m}$. The thin samples necessary for the push-out test were obtained by cutting $200 \mu \mathrm{m}$ thin sheets from the plate composite with a wire cutter. Subsequently, the sheets were manually polished using the same sequence as for the pushin samples, until the sheet thickness was in the range of $20-40 \mu \mathrm{m}$. They were placed on a metallic support with a central groove to carry out the fiber push-out tests. 


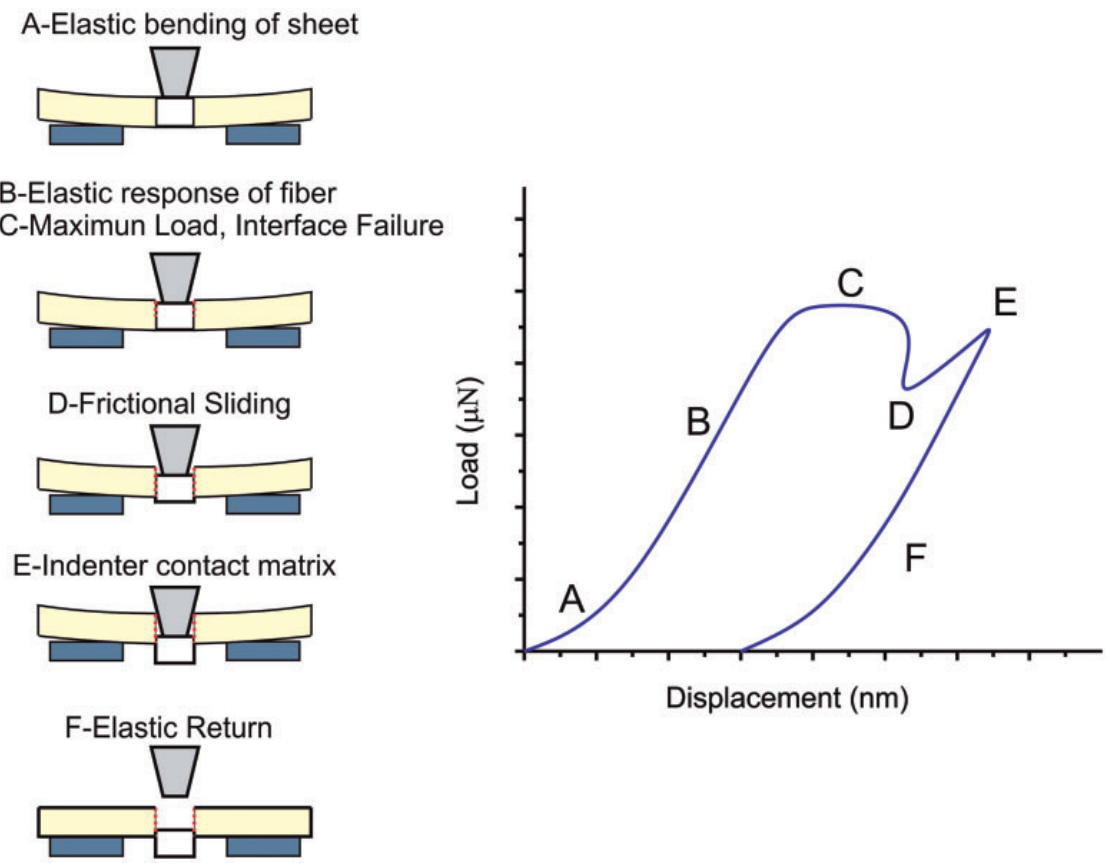

Figure I. Push-out test.

The tests were performed over 10 fibers per three samples (30 fibers in total) selected for each of the four materials. The fibers were tested with different neighborhood to obtain an average IFSS value.

Push-out test. In the push-out test, an individual fiber of a thin sheet of composite is loaded until fiber sliding occurs. The force applied to the fiber leads to the complete fracture of the fiber/matrix interface, and the fiber is pushed out of the thin sheet. ${ }^{2,22}$ In general, the forcedisplacement curve of the push-out test has three regions (see Figure 1). The initial region corresponds to elastic bending of the composite sheet between the supports. The next region corresponds to elastic deformation of the fiber by the action of the indenter; this region ends abruptly with the fracture of the interface and the sliding of the fiber in the sheet, leading to a maximum in the load. The average shear stress at the fiber/matrix interface is given by

$$
\tau=\frac{P}{2 \pi r e}
$$

where $P$ is the applied load, $r$ is the fiber radius, and $e$ the sheet thickness and the IFSS is given by equation (1) from the maximum load in the push-out test.

Push-in test. The push-in test is performed by loading an individual fiber within the composite until interface fracture occurs. ${ }^{24-28}$ The load-displacement curve $(P-u)$ presents an $\mathrm{S}$ shape (see Figure 2), and the initial region corresponds to an imperfect contact between the indenter and the fiber. This is followed by a linear region (with slope $S_{0}$ ) due to the elastic deformation of the fiber and the matrix, which is followed by a non-linear region due to the onset of interface failure. $^{27,28}$ The IFSS can be determined from the critical load $P_{c}$ at the onset of interface failure through the shear-lag model ${ }^{27-29}$ :

$$
\mathrm{IFSS}=\frac{n P_{c}}{2 \pi r^{2}}
$$

where $n$ is a parameter that depends on the elastic properties of the fibers and the matrix and also on the constraint induced by the surrounding fibers in the composite. $n$ can be determined from the slope of the $P-u$ curve in the linear region, $S_{0}$, as shown in Rodríguez et al., ${ }^{28}$ according to:

$$
n=\frac{S_{0}}{\pi r E_{f}}
$$

where $E_{f}$ is the longitudinal elastic modulus of the fiber.

\section{Results}

\section{Push-out tests}

The shear stress depth obtained during the push-out tests are plotted in Figure 3, where the shear stress was computed from equation (1). The differences in 


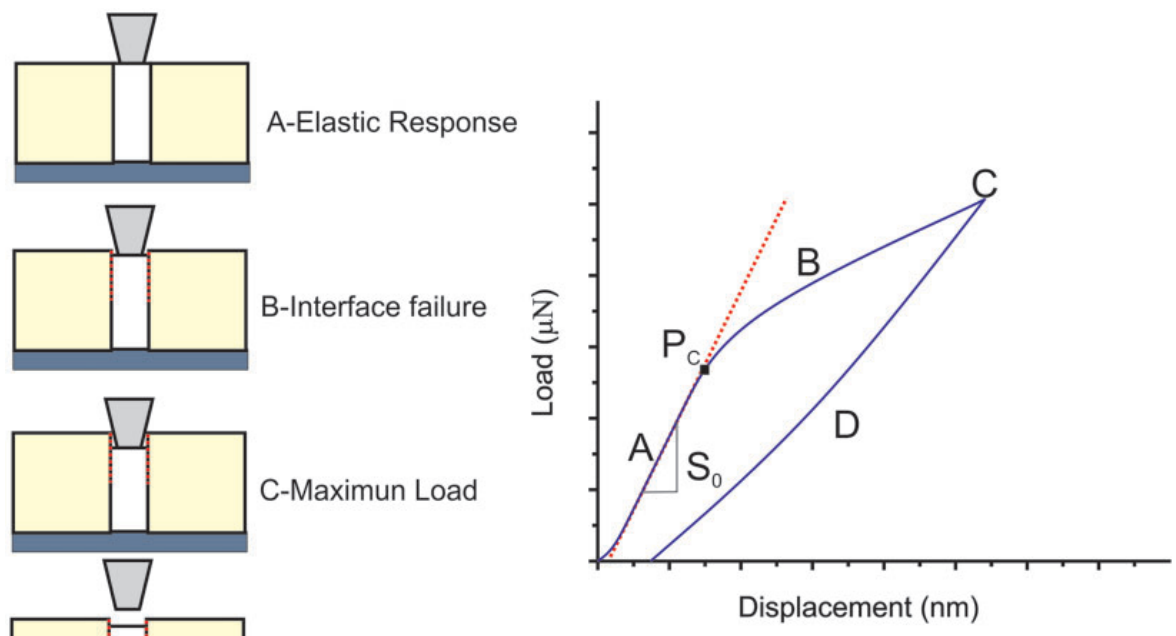

D-Elastic return

Figure 2. Push-in test.
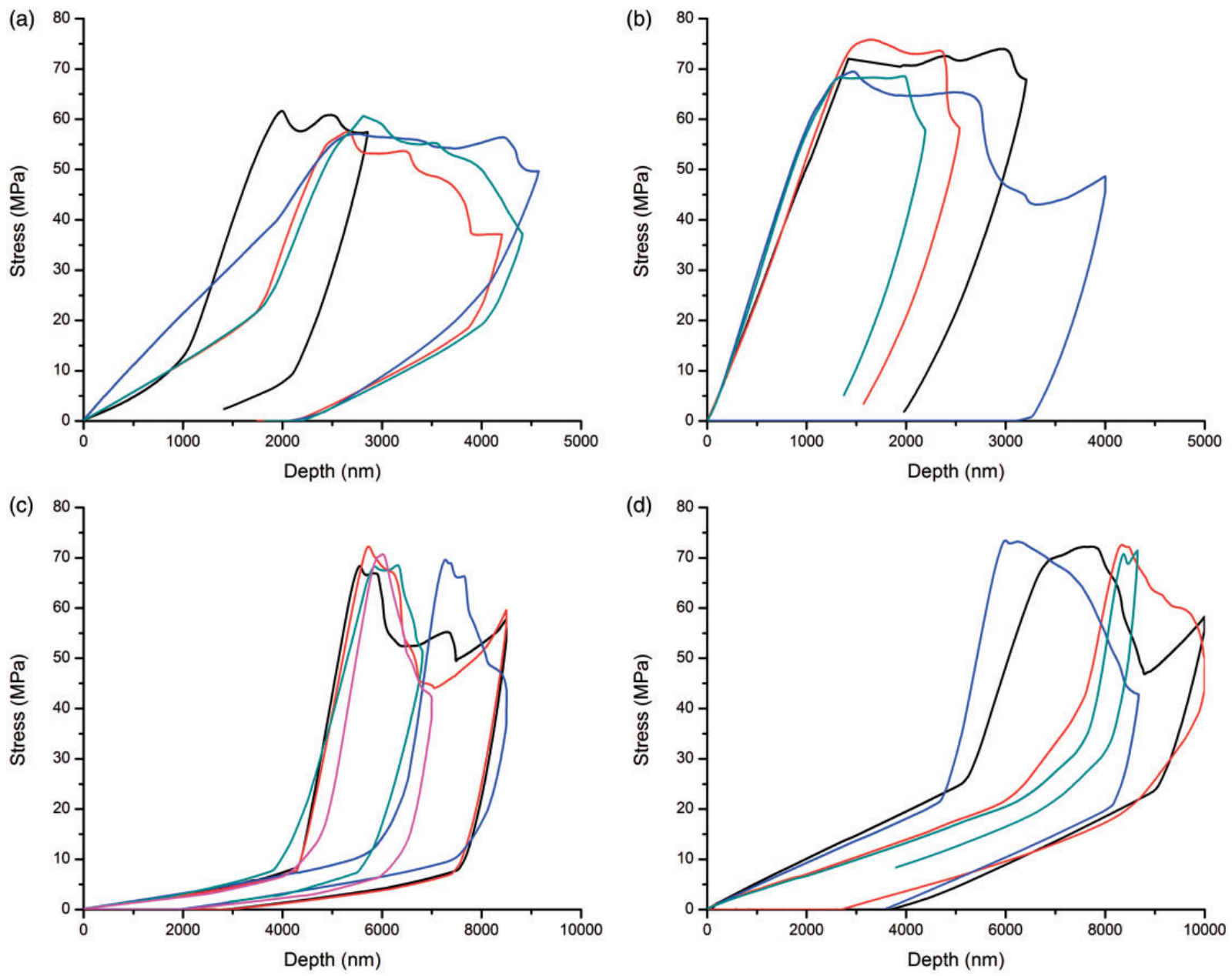

Figure 3. Experimental curves of push-out test. (a) EGI, (b) EG2, (c) EG3, (d) EG4. 


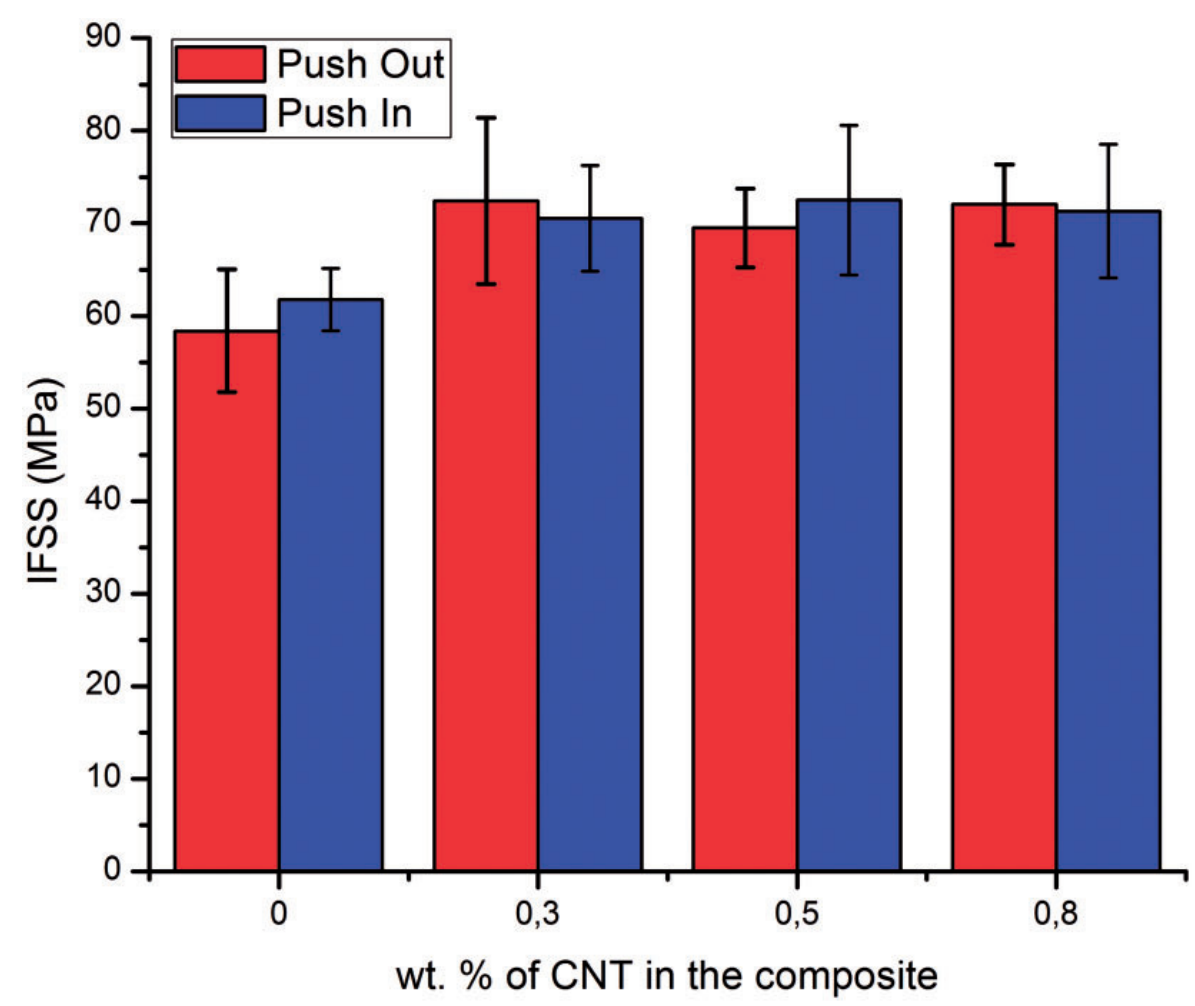

Figure 4. IFSS obtained from the push-out and push-in tests as a function of the CNT content in the composite.
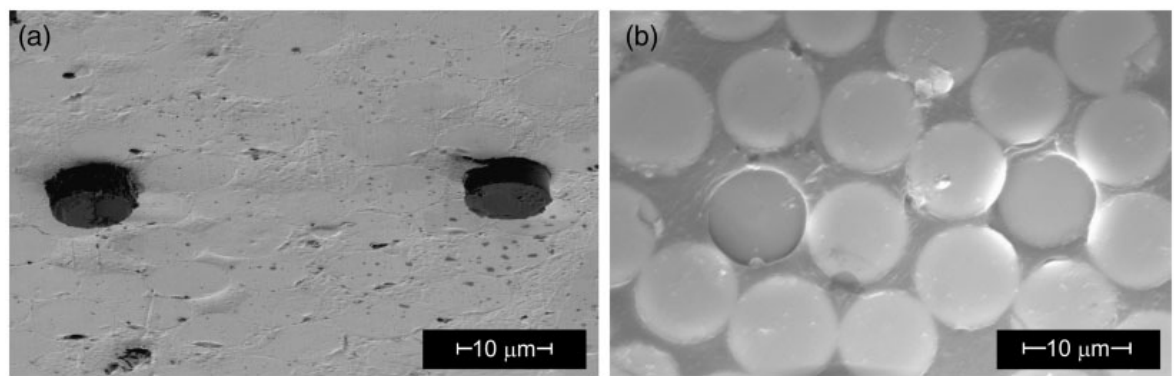

Figure 5. Scanning electron micrographs of pushed-out fibers. (a)

(a) Top surface of the sheet, (b) bottom surface of the sheet.

the initial shape of the curves are due to the actual location of the fiber within the sample. For instance, elastic bending of the composite sheet was very important in the samples shown in Figure 3(c) and (d) and negligible in the case of Figure 3(b). Nevertheless, the maximum load in the test (that dictates the IFSS) was independent of these features.

The IFSS was obtained from the experimental results from the maximum load in the test according to equation (1) and is plotted in Figure 4 as a function of the CNT content in the composite.

After the push-out test, selected samples were examined in the scanning electron microscope. The fibers tested were clearly seen on top and bottom surfaces of the sample (see Figure 5).

\section{Push-in test}

The load-depth obtained during the push-in tests for each composite material are plotted in Figure 6. There is a slight difference between the samples without CNT (EG1) and those with CNT (EG2, EG3, EG4).

After the push-in test, the topography of the sample surface was scanned by means of atomic force microscopy (Figure 7). The fiber was pushed in during the test and the flat indenter has led an imprint of approximately $0.2 \mu \mathrm{m}$ in depth in the center of the fiber. This imprint (due to the plastic deformation of the glass fiber during the test) together with the elastic deformation of the fiber was not considered in the analysis of the push-in test and has to be removed from the 

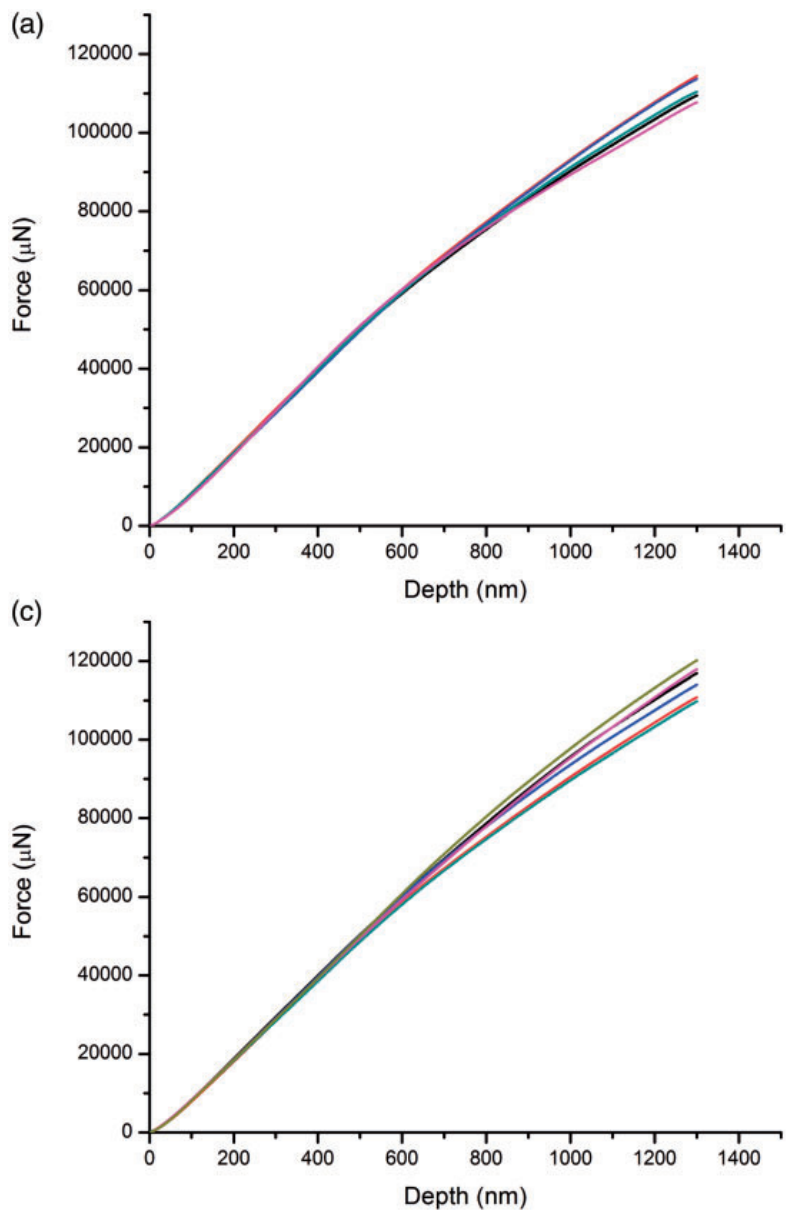

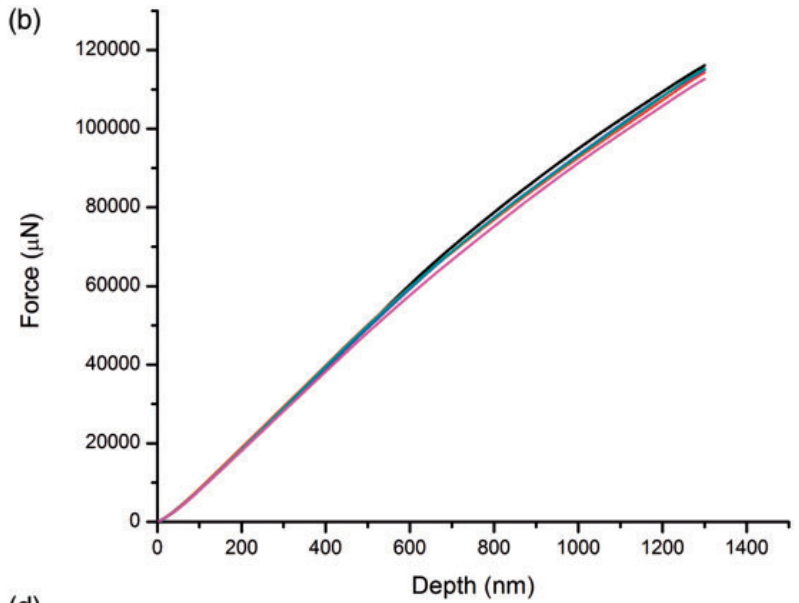

(d)

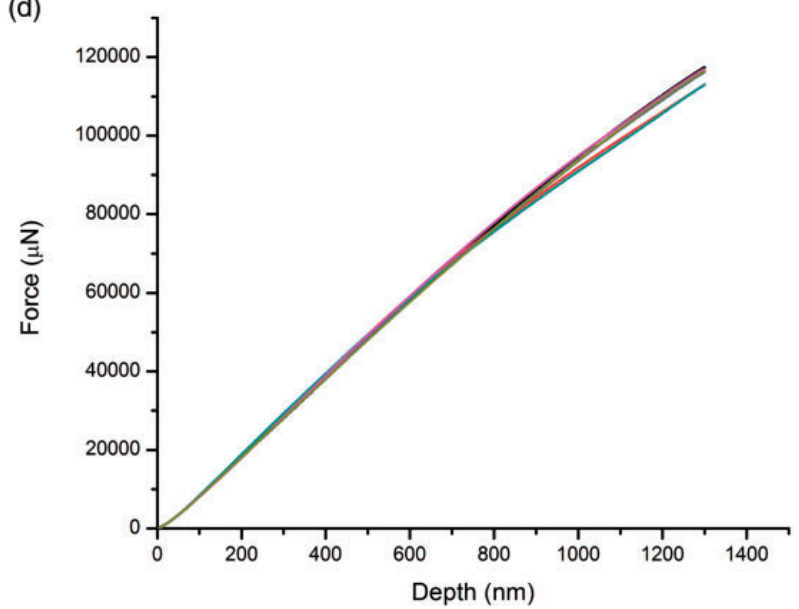

Figure 6. Experimental curves of push-in test, (a) EGI, (b) EG2, (c) EG3, (d) EG4.

(a)

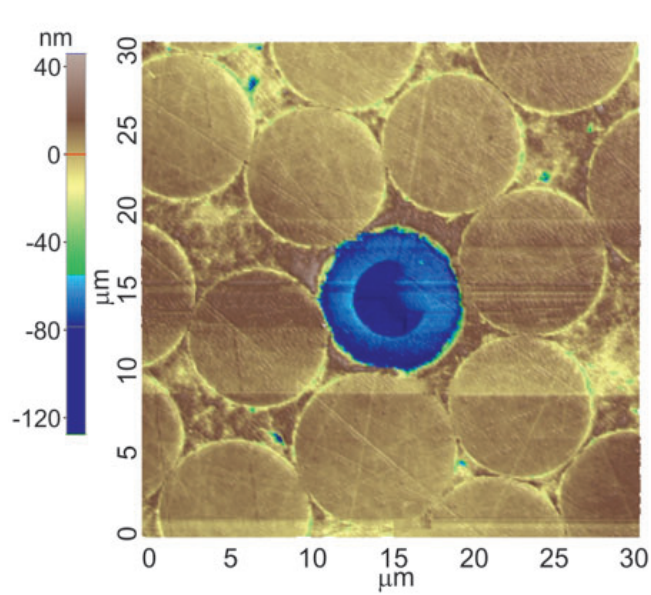

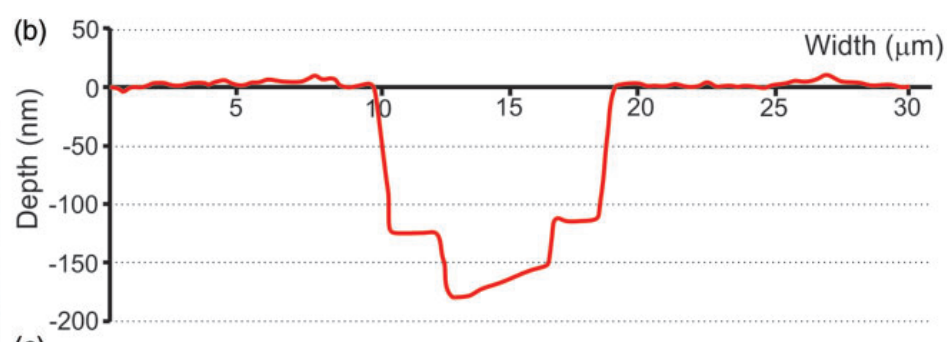

(c)

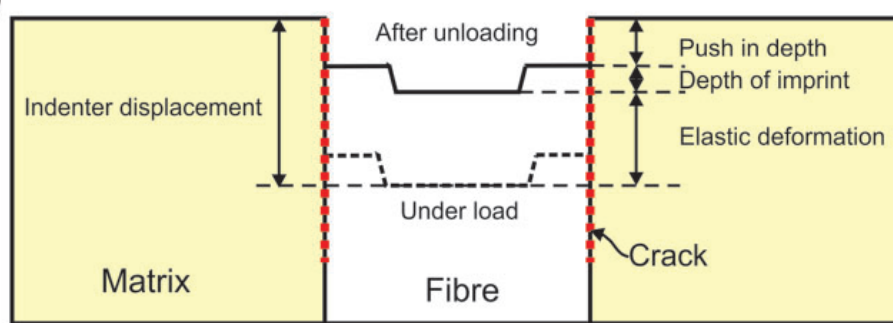

Figure 7. (a) Topography of the sample surface after the push-in test obtained by atomic force microscopy. (b) Depth profile of the push-in test measured by atomic force microscopy, (c) diagram of the displacements obtained in the push-in test. 

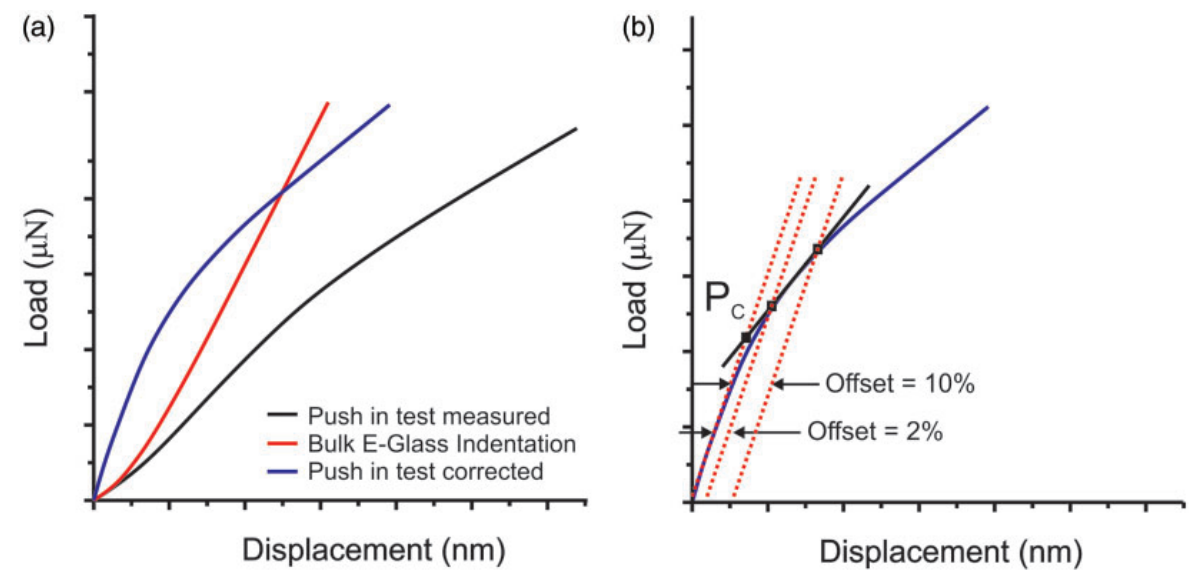

Figure 8. (a) Correction of the push-in curve by subtracting the bulk glass indention, (b) method used to determine the critical force.
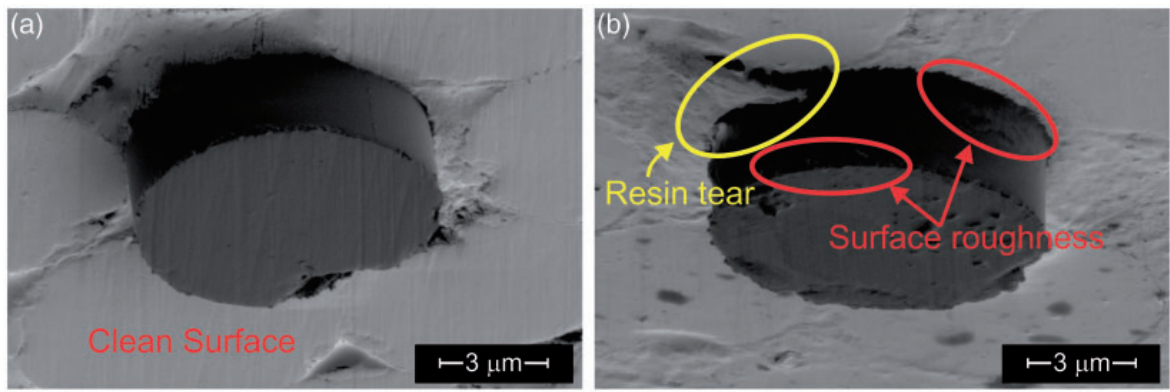

Figure 9. Scanning electron micrographs of pushed fibers. (a) EGI. (b) EG4.

load-displacement curve to compute the IFSS. ${ }^{25-27}$ To this end, two components in the displacement of the indenter have to be separated. The first one is related to the penetration of the indenter in the fiber, and the second one is associated with the displacement of the fiber with respect to the epoxy resin (see Figure 7(b) and (c)). The penetration of the indenter into the glass fiber as a function of the applied force was estimated by carrying out an indention in bulk glass sample (Figure 8(a)). The corresponding indentation depth for each load was subtracted from the total displacement in the experimental load-displacement curve to obtain the corrected curve which relates the applied load with the fiber displacement with respect to the matrix.

From the corrected curve, the critical load $P_{c}$ for the onset of interface failure was determined as the intersection point between two straight lines. ${ }^{28}$ Thus, a method was used in which the critical load is the intersection point of a straight line that goes through the points determined by two lines parallel to the initial stiffness, $S_{0}$, with offsets of $2 \%$ and $10 \%$ (see Figure $8(\mathrm{~b})$ ). The corresponding values of the IFSS as a function of the CNT content are plotted in Figure 4.

\section{Discussion}

Regardless of the differences in the micromechanical tests, the IFSS measured by the push-in and the pushout tests were very close for the materials analyzed and the differences were always within the experimental scatter (Figure 4). These results indicate that both methodologies are valid to measure the interface properties and the use of one or another will depend on the other factors. Sample preparation is easier in the case of the push-in test because it is only necessary to polish one surface of the composite perpendicular to the fibers while the preparation of the thin sheet of the composite may be very tedious in the case of the push-out test. Nevertheless, the IFSS is obtained directly from the maximum load during the test, the fiber diameter and the sheet thickness in the case of the push-out test while the experimental curves have to be post-processed in the push-in test to subtract the elastic deformation of the fiber and determine the critical load.

The CNTs led to $19 \%$ (average) increase in IFSS, independently of their concentration on the composite. It can be observed that on pushed fibers the CNTs 
show an effect on the interface failures modes. Without CNTs, the pushed fibers have a clean surface and no evidence of matrix damage (Figure 9(a)). On the contrary, configurations with CNTs present resin attached to the surface of the fibers and evidence of matrix tearing (Figure 9(b)).

The increment of the IFSS and the change on the failure modes were rationalized by Gorbatikh et al., ${ }^{4}$ who established that the presence of the CNTs contribute to a gradual transition from the stiff fiber to the compliant epoxy matrix reducing the stress concentration around the fiber and inducing a ductile failure on the matrix near the interface, also Lane et al. ${ }^{34}$ indicate that a soft (plastic) interface enhance the stress transfer from fiber to matrix.

\section{Conclusions}

The fiber/matrix IFSS was measured by means of pushin and push-out tests in glass/fiber epoxy composites containing different amounts of CNTs dispersed in the matrix. Both experimental methodologies provided very similar values of the IFSS for each material. It was found that the dispersion of CNTs increased in IFSS by $19 \%$ with respect to the composite without CNTs. This improvement was reached with $0.3 \mathrm{wt} . \%$ of CNTs and increasing the CNT content up to $0.8 \mathrm{wt} . \%$ did not improve the interface strength.

\section{Acknowledgments}

The content is solely the responsibility of the authors and does not necessarily represent the official views of the FONDEF. The authors would like to thank the Advanced Nanocomposites Research Group (GINA) belonging to Materials Engineering Department (DIMAT) at the University of Concepción, Chile.

\section{Conflict of interest}

None declared.

\section{Funding}

This study was financial supported by FONDEF No. CA12I10308 and Fondef IT 13i10054 Government of Chile. The authors would also like to thank the National Commission for Scientific and Technological Research, CONICYT (Ministry of Education-Government of Chile) by $\mathrm{PhD}$ scholarship grants $\mathrm{N}^{\circ} 21110094$ of $\mathrm{C}$. Medina M and to the CIPA, CONICYT Regional, GORE BIOBIO $\mathrm{R} 08 \mathrm{C} 1002$.

\section{References}

González C and LLorca J. Mechanical behavior of unidirectional fiber-reinforced polymers under transverse compression: microscopic mechanisms and modeling. Compos Sci Technol 2007; 67: 2795-2806.
Godara A, Gorbatikh L, Kalinka G, et al. Interfacial shear strength of a glass fiber/epoxy bonding in composites. Compos Sci Technol 2010; 70: 1346-1352.

Totry E, Molina-Aldareguia JM, González C, et al. Effect of fiber, matrix and interface properties on the in-plane shear deformation of carbon-fiber reinforced composites. Compos Sci Technol 2010; 70: 970-980.

Gorbatikh L, Lomov SM and Verpoest I. Nano-engineered composites: a multiscale approach for adding toughness to fibre reinforced composites. Procedia Eng 2011; 10: 3252-3258.

Godara A, Mezzo L, Luizi F, et al. Influence of carbon nanotube reinforcement on the processing and the mechanical behaviour of carbon fiber/epoxy composites. Carbon 2009; 47: 2914-2923.

Siegfried M, Tola C, Claes M, et al. Impact and residual after impact properties of carbon fiber/epoxy composites modified with carbon nanotubes. Compos Struct 2014; 111: 488-496.

Jones FR. A review of interphase formation and design in fibre-reinforced composites. J Adhesion Sci Technol 2010; 24: 171-202.

Kamae T and Drzal LT. Carbon fiber/epoxy composite property enhancement through incorporation of carbon nanotubes at the fiber-matrix interphase - Part I: the development of carbon nanotube coated carbon fibers and the evaluation of their adhesion. Compos Part $A$ 2012; 43: 1569-1577.

Bekyarova E, Thostenson ET, Yu A, et al. Multiscale carbon nanotube-carbon fiber reinforcement for advanced epoxy composites. Langmuir 2007; 23: 3970-3974.

Lachman N, Wiesel E, Guzman de Villoria R, et al. Interfacial load transfer in carbon nanotube/ceramic microfiber hybrid polymer composites. Compos Sci Technol 2012; 72: 1416-1422.

An Q, Rider AN and Thostenson ET. Hierarchical composite structures prepared by electrophoretic deposition of carbon nanotubes onto glass fibers. Appl Mater Interfaces 2013; 5: 2022-2032.

Zhang J, Deng S, Wang Y, et al. Effect of nanoparticles on interfacial properties of carbon fibre-epoxy composites. Compos Part A 2013; 55: 35-44.

Chandrasekaran VCS, Advani SG and Santare MH. Influence of resin properties on interlaminar shear strength of glass/epoxy/MWNT hybrid composites. Compos Part A 2011; 42: 1007-1016.

Lin Yang L, He X, Mei L, et al. Interfacial shear behavior of 3D composites reinforced with CNT-grafted carbon fibers. Compos Part A 2012; 43: 1410-1418.

Yilmaz YL. Analyzing single fiber fragmentation test data by using stress transfer model. J Compos Mater 2002; 36: 537-551.

Zhao YR, Xing YM, Lei ZK, et al. Interfacial stress transfer behavior in a specially-shaped fiber/matrix pullout test. Acta Mech Sinica 2010; 26: 113-119.

Agnihotri PK, Kar KK and Basu S. Cohesive zone model of carbon nanotube-coated carbon fiber/polyester composites. Model Simulation Mater Sci Eng 2012; 20: 035014. 
Zu M, Li Q, Zhu Y, et al. The effective interfacial shear strength of carbon nanotube fibers in an epoxy matrix characterized by a microdroplet test. Carbon 2012; 50: 1271-1279.

An F, Lu C, Li Y, et al. Preparation and characterization of carbon nanotube-hybridized carbon fiber to reinforce epoxy composite. Mater Design 2012; 33: 197-202.

Sockalingam S, Dey M, Gillespie JW, et al. Finite element analysis of the microdroplet test method using cohesive zone model of the fiber/matrix interface. Compos Part A 2014; 56: 239-247.

Chandra $\mathrm{N}$ and Ghonem $\mathrm{H}$. Interfacial mechanics of push-out tests: theory and experiments. Compos Part $A$ 2001; 32: 575-584.

Canal LP, Gonzalez C, Segurado J, et al. Intraply fracture of fiber-reinforced composites: microscopic mechanisms and modeling. Compos Sci Technol 2012; 72: 1223-1232.

Battisti A, Esqué-de los Ojos D, Ghisleni R, et al. Single fiber push-out characterization of interfacial properties of hierarchical CNT-carbon fiber composites prepared by electrophoretic deposition. Compos Sci Technol 2014; 95: 121-127.

Kalinka G, Leistner A and Hampe A. Characterisation of the fibre/matrix interface in reinforced polymers by the push-in technique. Compos Sci Technol 1997; 51: 845-851.

Zidi M, Carpentier L, Chateauminois A, et al. Quantitative analysis of the micro-indentation behaviour of fibre-reinforced composites: development and validation of an analytical model. Compos Sci Technol 2000; 60: 429-437.
Zidi M, Carpentier L, Chateauminois A, et al. Analysis of micro-indentation tests by means of an analytical model taking into account different interfacial responses. Compos Sci Technol 2001; 61: 369-375.

Molina-Aldareguía JM, Rodríguez M, González C, et al. An experimental and numerical study of the influence of local effects on the application of the fibre push-in tests. Philos Mag 2011; 91: 1293-1307.

Rodríguez M, Molina-Aldareguía JM, González C, et al. A methodology to measure the interface shear strength by means of the fiber push-in test. Compos Sci Technol 2012; 72: 1924-1932.

Doan TTL, Gao SL and Mäder E. Jute/polypropylene composites I. Effect of matrix modification. Compos Sci Technol 2006; 6: 952-963.

Herrera-Franco PJ and Valadez-Gonzalez A. A study of the mechanical properties of short natural-fibre reinforced composites. Compos Part B 2005; 36: 597-608. Warrier A, Godara A, Rochez O, et al. The effect of adding carbon nanotubes to glass/epoxy composites in the fibre sizing and/or the matrix. Compos Part A 2010; 41: $532-538$.

Korayem AH, Barati MR, Simon GP, et al. Reinforcing brittle and ductile epoxy matrices using carbon nanotubes masterbatch. Compos Part A 2014; 61: 126-133.

Aravand M, Lomov SV, Verpoest I, et al. Evolution of carbon nanotube dispersion in preparation of epoxybased composites: from a masterbatch to a nanocomposite. eXPRESS Polym Lett 2014; 8: 596-608.

Lane R, Hayes SA and Jones FR. Fibre/matrix stress transfer trough a discrete interphase: 2. High volume fraction systems. Compos Sci Technol 2001; 61: 565-578. 